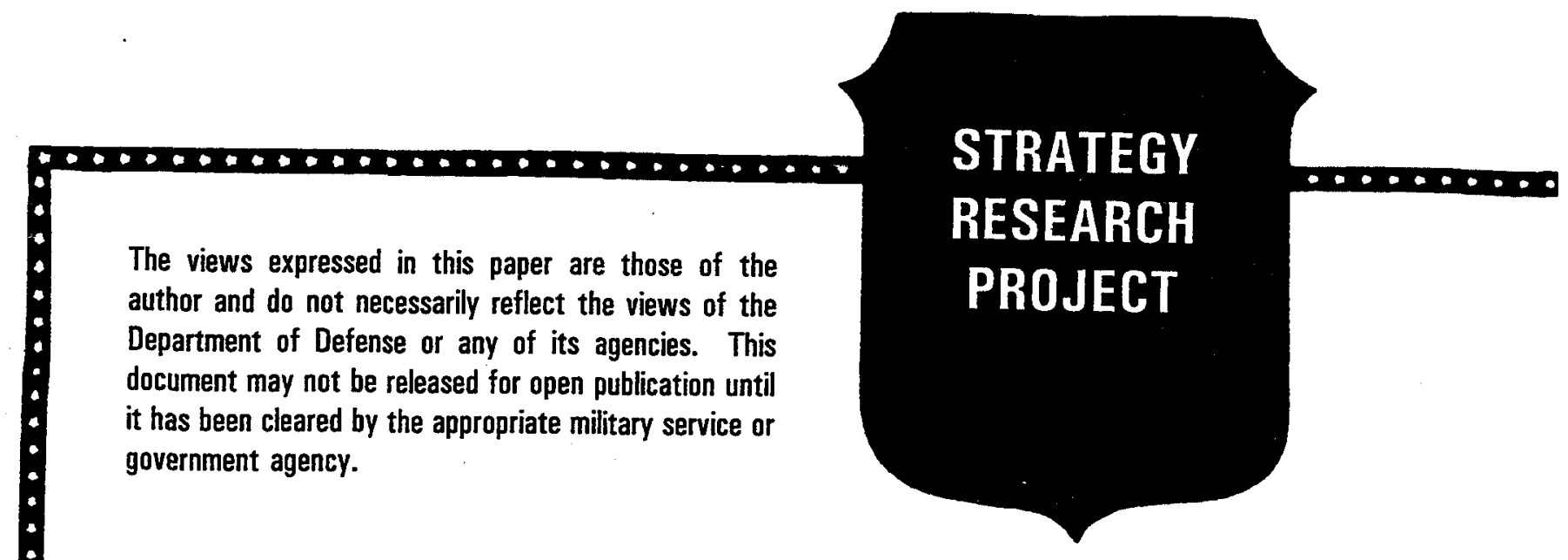

\title{
COUNTERPROLIFERATION: THE EMPEROR HAS NO CLOTHES
}

\author{
BY \\ LIEUTENANT COLONEL EDWARD W. NEWING \\ United States Army
}

DISTRIBUTION STATEMENT A:

Approved for public release.

Distribution is unlimited

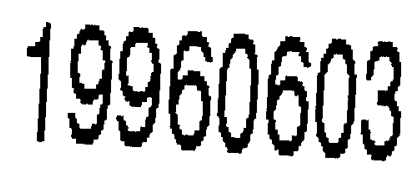

ging

USAWC CLASS OF 1996

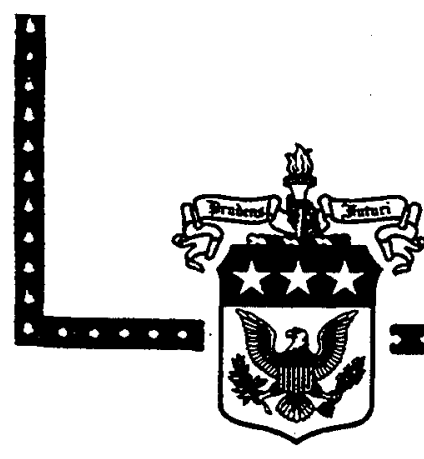

U.S. ARMY WAR COLLEGE, CARLISLE BARRACKS, PA $17013-5050$ 


\section{THE PAGES IN THIS DOCUMENT}

WERE MISNUMBERED

\section{PAGES 16 THRU 25 HAVE BEEN RENUMBERED \\ PER: Brenda Redcay}

(717) $\quad 245-4317$

U.S. ARMY WAR COLLEGE

CARLISLE BARRACKS, PA. 


\section{UNCLASSIFIED}

\section{USAWC STRATEGY RESEARCH PROJECT}

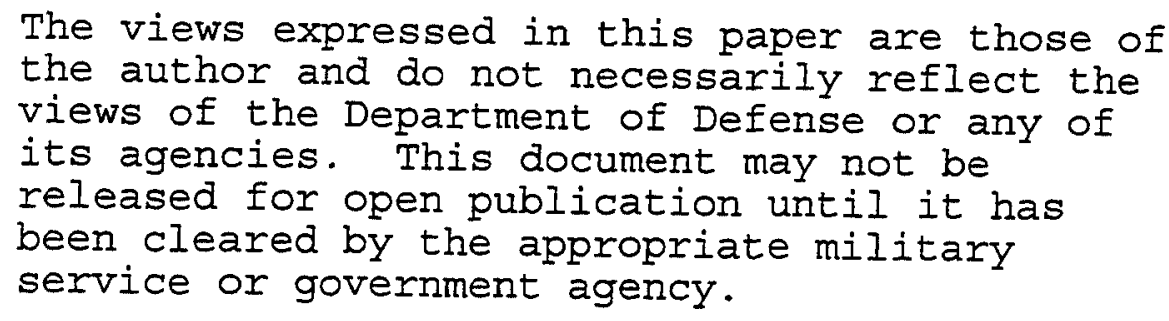

COUNTERPROLIFERATION: THE EMPEROR HAS NO CLOTHES

by

\section{Lieutenant Colonel Edward W. Newing United States Army}

\section{Colonel Shand H. Stringham Project Advisor}

DISTRIBUTION STATEMENT A: Approved for public release. Distribution is unlimited.

\section{U.S. Army War College}

Carlisle Barracks, Pennsylvania 17103

\section{UNCLASSIFED}




\begin{abstract}
AUTHOR: Lieutenant Colonel Edward W. Newing, USA

TITLE: Counterproliferation: The Emperor Has No Clothes

FORMAT: Strategy Research Project

DATE: 3 April 1995 PAGES: 25 CLASSIFICATION: Unclassified

The proliferation of Weapons of Mass Destruction and their means of delivery is a National Emergency. The National Security Strategy and National Military Strategy admirably highlight counterproliferation as urgent national priorities. Despite these well intentioned efforts, counterproliferation initiatives, begun in 1993, have to date only yielded grand policies and little progress. Lack of national leadership, multiplicitous and overlapping programs, interagency friction, and misplaced priorities could doom the laudable efforts to failure. As the National Command Authority seeks to dress themselves in a cloak of protection against the threats of weapons of mass destruction, who is brave enough to tell them the Emperor has no clothes? This assessment covers counterproliferation strategies via an ends, ways, and means methodology, analyzes the complexity of current initiatives, and provides benefits and challenges to the eight areas of the Counterproliferation Support Program. After conclusions about the illusionary success of these efforts, the assessment offers recommendations to enhance meaningful progress.
\end{abstract}




\section{"One of our most urgent priorities must be attacking the proliferation of weapons of mass destruction, whether they are nuclear, chemical, biological, and the ballistic missiles that can rain them down on populations hundreds of miles away." (President Clinton's address to UN General Assembly, Fall 1993)}

The danger of proliferation of weapons of mass destruction (WMD) and their means of delivery continues to be a national emergency. Complex strategies are underway to make this a safer world where, despite our best efforts, nations capable of employing weapons of mass destruction are still increasing. ${ }^{2}$ Reducing these pervasive threats is a part of our National Strategy, National Military Strategy, and recent policy initiatives. Despite a welcome linkage in the strategic flow from National Security Strategy to National Military Strategy, the emerging concepts to achieve multiplicitous counterproliferation programs are confused and diluted. Unfortunately, lack of leadership, nonproliferation traditionalism ${ }^{3}$, competing bureaucracies, and misplaced focus plague the overall effort. Throwing money at the problem or building squanderous policy regimes often builds a sense of false security. We are letting our leader parade down a dangerous international path draped in an imaginary protective suit. Is anyone brave enough to tell the emperor that he has no clothes?

While this assessment may sound a bit cynical, it is actually therapeutic. By assessing the evolving strategies to reduce weapons of mass destruction and their means of delivery, perhaps more priority and synergy will enhance national efforts. Using a strategic thought model of ends, ways, and means to analyze counterproliferation, one can see it is the "ways" and "means" which could lead to ineffectiveness. This review highlights the complexity of multidimensional efforts, perhaps the causative agent of illusionary progress. Rather than stop at finger pointing and carping, this assessment of counterproliferation offers some quick conclusions about risks of current approaches and recommends some "ways" to improve. 
Proliferation of weapons of mass destruction is unquestionably a national emergency. Three Presidential Executive Orders, 12735 (November 1990), 12930 (September 1994), and 12938 (November 1994) declared nuclear, biological, and chemical weapons, and their means of delivery direct threats to the security of the nation and solicited efforts to strengthen U.S. response to proliferation problems ${ }^{4}$. Echoes of the critical nature of this issue were heard in strong and unambiguous statements by three past Directors of Central Intelligence, two former Chairmen of the Joint Chiefs of Staff, three former Secretaries of Defense, two former Secretaries of State, as well as numerous bipartisan efforts by members of Congress. Perhaps the most striking priority about these issues came to light when weapons of mass destruction were highlighted in the Department of Defense (DoD) Bottom-Up Review as one of the four greatest dangers in a post Cold War security environment. ${ }^{5}$ If WMD is such a crucial issue, what national energy is devoted to it?

"A National Security Strategy of Engagement and Enlargement", published in February, 1995, treats WMD as a major threat to our security, our allies, and other friendly nations. $^{6}$ A key part of the strategy treats nonproliferation and counterproliferation as critical priorities. It highlights a broad spectrum of programs spanning prevention to protection. The "ends" of the strategic thought process - Combat the Spread and Use of WMD and Missiles is clear. The "ways" are broad groups of diplomatic, arms control, legislative, and military initiatives. The "means" emerge as a host of international players, government agencies, and DoD resources. For the first time in a decade, the National Security Strategy establishes WMD as a major threat and formally proposes to do something about them. The potential military ways and means of achieving the strategy are as broad as the other national efforts 
challenged by proliferation.

The "National Military Strategy of the United States of America, A Strategy of Flexible and Selective Engagement," published in 1995, acknowledges the danger of proliferation of WMD in the world environment and folds its broad area response into two national military objectives of promoting stability and thwarting aggression. ${ }^{7}$ Descending from general objectives, the military response to WMD is found as enabling approaches through peacetime engagement (security assistance), deterrence and conflict prevention (nuclear, arms control), as well as fight and win (countering WMD). ${ }^{8}$ With all the tailors in the kingdom assembled and ready to weave, what does this cloak of prevention and protection from the evil of WMD look like?

Throughout the National Security Strategy and National Military Strategy there is no clear distinction between nonproliferation and counterproliferation. Energized by these national strategies, various government and non-government agencies scramble to develop often overlapping policies designed to lessen the continuing threat of proliferation. Additionally, some view counterproliferation as a broad visionary approach to security in a post-Cold War world while others perceive the initiative as narrow sets of military action. ${ }^{9}$

While the objectives of both nonproliferation and counterproliferation responses are valid, the inherent competition underscores the complexity and inefficiency which plague efforts to combat WMD proliferation. Prevention activities, such as arms control, trade agreements, and economic sanctions, are interagency affairs and generally follow a nonproliferation approach. Protection activities, such as defusing, deterrence, offensive and defensive actions are mostly DoD affairs and characterize a counterproliferation approach. ${ }^{10}$ 
There is obvious overlap of governmental responsibilities in the middle of the spectrum and ample room for shared efforts. Shared responsibilities of the WMD tailors also spawn obvious competition for budget share, agency turf battles, and create an infuriating slowness in fashioning the Emperor's clothes.

The counterproliferation initiative, announced by Les Aspin in December 1993, is a drive to develop new military missions and capabilities to protect against proliferation. ${ }^{11}$ Going beyond the traditional nonproliferation activities to more aggressive strategies, there is an acknowledgment that proliferation is not just a diplomatic problem, but also a military threat. The initiative appears to be a holistic approach in which DoD shares interagency responsibility in traditional nonproliferation (diplomatic) responses and takes special responsibility toward the newer and more encompassing counterproliferation (military) end of the spectrum. ${ }^{12}$

The response to the proliferation threats embraces a strategy which has eight basic elements. In the prevention category, the elements are dissuasion, denial, arms control, and international pressure. In the protection category, the elements are defusing, deterrence, offense, and defense. ${ }^{13}$ The counterproliferation strategy casts a long shadow of involvement in all elements.

Dissuasion involves convincing nations not to obtain WMD. ${ }^{14}$ Many nations seek WMD for prestige, national security, balance of power, or deterrence against regional powers who maintain WMD programs. Providing security assurances, both positive and negative, may work to overcome perceived vulnerabilities and convince nations who do not yet have $\mathrm{WMD}$, not to develop them. Successful dissuasion requires the employment of diplomatic, 
economic, and military elements of power.

Denial involves restriction of technology, sources, and components for the research, development, production, manufacture, and stockpiling of WMD weapons and the means of delivery. ${ }^{15}$ These elements require multilateral cooperation to be successful.

Arms control involves commitment to treaties and agreements which help to stabilize and reduce proliferation. ${ }^{16}$ While the ultimate goal of total disarmament may be a desired endstate, WMD arms control efforts center on reduction of nuclear weapons and their means of delivery and hopeful elimination of chemical and biological weapons. The Nuclear Nonproliferation Treaty, Antiballistic Missile Treaty, Biological Weapons Convention, Chemical Weapons Convention, and many bilateral agreements, are all arms control efforts which require continuous engagement through confidence and security measures to be successful.

International pressure involves punitive actions against nations proven or suspected to be treaty or agreement cheaters and those nonsignatory nations which contribute to proliferation ${ }^{17}$. The use of diplomatic, economic, and military elements of power along with multilateral sanctions seek to stem the tide of proliferation.

Defusing involves actions to reduce the proliferation threat by nations which possess $\mathrm{WMD}^{18}$. Treaty verification, $\mathrm{WMD}$ destruction, and development of confidence and security measures require the skillful use of all elements of national power as well as international cooperation.

Deterrence is an art which ultimately portrays the risk of proliferation of WMD and their means of delivery as too high. ${ }^{19}$ The post Cold War deterrence approaches require new 
regional security assessments as well as reexamination of current means of persuasion and willingness to use a wide range of response.

Offense involves action to seize, disable, or destroy WMD and their means of delivery. ${ }^{20}$ While associated mostly with the military, offense may also encompass interagency or international response to threats of WMD proliferation by nation-states, groups, or individuals.

Defense involves active and passive measures to reduce the effects of WMD and create little gain for adversaries. ${ }^{21}$ Comprehensive efforts to strengthen individual and group survivability while reducing vulnerability are essential requirements for this part of the counterproliferation strategy.

The evolution of a counterproliferation strategy began at the highest level of national security strategy and national military strategy. In policy development it expanded to capture prevention as well as protection, and in doing so, straddles both traditional nonproliferation and counterproliferation elements and activities. Counterproliferation enjoys the support of the Executive Office, Congressional leaders, and increasingly, the public. The "ends" and "ways" of the strategy appear to be coherent and the emperor still has the greatest of expectations. Until there is a closer look at the "means" the emperor's fine cloak remains to be seen.

Much of the "means" of the counterproliferation strategy is found in DoD's Counterproliferation Support Program (CSP). It encompasses eight ambitious areas to achieve the protection elements of the strategy: battlefield surveillance, strategic and tactical intelligence, proliferation prevention, counterforce, covert operations, active defense, passive 
defense, and systems analysis/studies ${ }^{22}$ Since the December 1993 announcement of the initiative, policy guidance and budget shifting dominated counterproliferation efforts. The Counterproliferation Support Program unites existing DoD counterproliferation related programs and places emphasis on accelerating development of new technologies, research, and systems ${ }^{23}$ As these programs evolve, the regional and functional Combant Commanders and the Services are in the process of developing military requirements to support each mission area. Each program element of the counterproliferation has strengths and weaknesses. The success of each of these "means" will determine the success of the strategy. Battlefield surveillance is crucial to counterproliferation initiatives. Sensing proliferation activities or identifying patterns leading to the employment of WMD provides the National Command Authority and other governmental agencies critical early warning and notification. With adequate early detection which gives rise to early warning, strategic as well as operational and tactical planning can focus to halt proliferation events or diminish WMD effects.

There are existing means of surveillance which provide a limited capability. Joint Surveillance Target Acquisition and Reconnaissance Systems, Airborne Warning and Control System, National Technical Means, and human sources may reveal proliferation activities. Modernization in this area seeks to add fidelity to currently available sources.

The challenge of surveillance is that it is generally difficult to detect proliferation or spot the smoking gun. Even with a host of surveillance devices, WMD and missile proliferation may appear to be legitimate industrial activities. Fertilizer plants, breweries, pharmaceutical industries, or firms producing space launch components offer many dual use 
opportunities for both peaceful and offensive purposes. WMD activities are driven increasing underground or masked in ways that only the most intrusive means can be used to detect suspect areas.

Another view of surveillance is that current capabilities are as good as they can be, especially in concert with other counterproliferation budget requests. Resources aimed at modernization of this potential means might be spent better elsewhere. Unless forces demand 24 hours per day vigilance and foolproof means are available, investment to further refine this area of technology should go to a higher priority deficiencies in the battle of counterproliferation. DoD proposed $\$ 9.6 \mathrm{M}$ in battlefield surveillance as part of the larger package of $\$ 108 \mathrm{M}$ needed in 1996 to accelerate counterproliferation efforts. ${ }^{24}$ It may be possible the resolution of battlefield surveillance deficiencies are not significant needs when compared to the $\$ 3.8 \mathrm{~B}$ request for ongoing related counterproliferation programs. The ultimate goal of enhancements in surveillance hope to provide increased capability (however meager) to detect, identify, and characterize threats. No other counterproliferation element is more dependent on excellent resolution than strategic and tactical intelligence.

Improvement of strategic and tactical intelligence can ultimately determine the success of counterproliferation efforts. Larger than the military contribution, strategic intelligence involves the entire intelligence community. To counter the increase in WMD and their means of delivery, the U.S. intelligence community now has aggressive programs to identify international WMD programs, assess intentions, discover clandestine transfer networks to obtain restricted material or launder money, and overcome denial and deception programs. ${ }^{25}$ Even with gains in the number of nations signing up to nonproliferation regimes, there is a 
severe challenge of deception and concealment by both signatory and non-signatory nations to multilateral treaties and agreements.

Despite the importance of this key element of counterproliferation, strategic and tactical intelligence received no new Counterproliferation Support Program funds. ${ }^{26}$ The intelligence community, while performing superbly within their own budget authorities, illustrates the basic confusion over what is nonproliferation and what is counterproliferation. The Central Intelligence Agency's Nonproliferation Center, focus of intelligence for WMD, regards nonproliferation as consisting of four aspects: prevent acquisition, roll-back existing capabilities, deter weapons use, and adapt military forces to respond to threats. ${ }^{27}$ As agencies posture for primacy and debate responsibilities, there can be increased competition for budget shares.

In addition to surveillance and intelligence, proliferation prevention represents a discrete element of the Counterproliferation Support Program. The DoD, seeing the need to expand beyond the protection realm, requested $\$ 2.8 \mathrm{M}$ for prevention activities. ${ }^{28}$ Dissuasion, denial, arms control, and international pressure encompass a broad basket of responses for which DoD has vested interests and participation. Military experts participating in verification programs, enforcement of sanctions, intelligence sharing, technology development, and security assistance are viable roles. Efforts to close operational gaps in prevention activities are still under development.

Counterforce is the largest resource area requested in the Counterproliferation Support Program. The pointed end of the spear is $\$ 52.5 \mathrm{M}$ and nearly half of $\$ 108 \mathrm{M}$ budget request for $1996{ }^{29}$ As mentioned before, regional and functional Combatant Commanders are still 
developing military requirements, but clearly the capability to destroy WMD and their means of delivery appears to be the highest priority of all counterproliferation needs. Some of the programs in the counterforce area include smart bombs and specialized warheads with superhot burning explosives. ${ }^{30}$ Other technology initiatives related to counterforce of WMD are attacking hardened or underground facilities while reducing the spread of contamination, especially smart fuzes to trigger explosions after a sequence of penetrations, and munitions which provide feedback to pilots. ${ }^{31}$

With a realistic view, counterforce is essential because nonproliferation actions and prevention activities are not foolproof. Even in a climate of improved WMD and ballistic missile control regimes, there are twenty-five countries that have or are developing capabilities. ${ }^{32}$ Some of these nations are known to export WMD and missile technologies to third countries or groups. ${ }^{33}$ The safe approach is to recognize proliferation of WMD continues and that enhancement of our capabilities to eliminate those sources is paramount. As discovered during the Gulf War, ambitious targeting and relentless attack on an adversary's WMD infrastructure reduces the threat, but is not an end in itself. Also learned, was a combination of prevention and protection is imperative to reduce uncertainties.

Another view is our ability to use counterforce against WMD and their means of delivery is adequate and resources needed to improve are overstated. We can certainly destroy bunkers, production facilities, storage and transfer sites with impunity. Precision guided weapons, although not perfect and certainly ineffective against deception sites or elusive targets like mobile launchers, are adequate out to the mid-term of modernization (5-7 years). New technologies sought by counterforce enhancements to destroy extremely deep 
bunkers or destroy WMD agents without harmful collateral effects have some merit but begin a perpetual and costly game of measure-countermeasure-counter-countermeasure.

The tremendous budget demands in counterforce may be a reflection of some defense programs to salvage modernization lost through other budget reduction efforts. It is obvious that identification with the Counterproliferation Initiative increases a program's visibility and improves prospects for support in budget deliberations. ${ }^{34}$ Many of enhancements in the Counterforce area are preprogrammed improvements to existing conventional weapon systems which can be applied to conventional or WMD targets. The Counterproliferation Support Program is sufficiently expansive to allow for reprogramming of less value added enhancements to more dramatic areas of deficiency.

Covert operations of the Counterproliferation Support Program reflect a growing need to circumvent efforts by proliferators to conceal and deny access to WMD programs. The expansive and adaptive capabilities of Special Operational Forces have tremendous application in a wide range of potential counterproliferation activities. The $1996 \mathrm{DoD}$ request for this element was $\$ 4.9 \mathrm{M},{ }^{35}$ however it is the effects, not the amount of investment, which can be the measure of success at thwarting potential proliferants. Many of the Special Operations mission areas, direct action, unconventional warfare, special reconnaissance, and counterterrorism may be called upon to support protective actions of counterproliferation.

Covert operations could present interesting challenges for the President. While sanctioned by the National Command Authority, preemptive strikes or raids may be perceived as violations to international law. Active self defense, as defined in the United Nations charter, or rationalized by Presidential findings, runs the risk of condemnation by allies, 
regional partners, or global competitors. The capability for conducting covert and counterforce operations is one of many elements for counterproliferation. If all else fails, we need the capability to survive WMD attacks with credible and robust defensive measures.

Active Defense provides a valuable pillar of protection in the counterproliferation initiative. Active defense is a variety of measures to protect selected assets and forces from attack by destroying means of delivery. For WMD and their means of delivery, active measures include destroying airborne launch platforms or theater missiles in flight.

Theater Missile Defense (TMD) is a large part of Active Defense. As with strategic and tactical intelligence elements of the Counterproliferation Support Program, Active Defense received only current base program funds and no new CSP funds. ${ }^{36}$ It is difficult to dispute the value of TMD, but the program is so complex it is rarely completely understood (or supported in full). The objective of TMD operations is to integrate mutually supporting passive defense, attack operations, active defense, and battle management of command, control, coordination, and computers. The primary threat of WMD to our forces is by long range missiles and aircraft. TMD links active defense measures with passive and attack operations to provide coordinated sensor input, threat assessment, rapid warning, targeting, and post strike assessment.

The fate of the active defense element of the counterproliferation program is tied to success in the TMD area. Challenges to Ballistic Missile Defense, National Missile Defense, and fluctuating interpretations of the Anti-Ballistic Missile Treaty invariably affect TMD program designs and objectives. While recognized as a reasonable means to bolster counterproliferation, TMD is often considered not affordable in total. This area, as with the 
next, passive defense, has the objective of reducing the success of a WMD attack and with proper defenses convince a potential adversary there is little to gain.

Passive defense is one of the most important elements to countering weapons of mass destruction, yet it remains the most inadequate and neglected area of counterproliferation efforts. ${ }^{37}$ All Services traditionally relied on offensive means and deterrence while placing meager investments in defensive training and equipment. Spurred by Congress after Operation Desert Storm, DoD centralized its management of WMD funds to reduce redundancies and achieve improved readiness. The Army, as DoD Executive Agent for chemical and biological defensive research, development, testing, and evaluation, works through the Joint Requirements Oversight Council (JROC) for modernized nuclear, biological, and chemical defense equipment.

The major benefit to having strong defenses is that it negates most advantages an aggressor seeks to gain by the employment of nuclear, biological, and chemical weapons. WMD defenses can significantly diminish potential casualties and serve as a safeguard if other means of deterrence fail. In the post-Cold War era, the need to bolster defenses is even more important as proliferation of WMD increases. Despite improvements in the number of nations which sign on to multilateral treaties and agreements, the number of countries which possess or pursue WMD programs still increase, including many signatories of WMD conventions and arms control agreements. ${ }^{38}$

DoD counterproliferation efforts include passive defense measures such as improved immunizations, detection, protection, and decontamination. Each Service participates in Joint material, doctrine, organizations, and logistics fora to identify and prioritize enhancements for 
WMD defensive readiness. The Counterproliferation Support Program recognizes these ongoing efforts and seeks funds to accelerate technologies and fielding of detection equipment. ${ }^{39}$ For example, the program will test chemical and biological detection systems carried by Unmanned Aerial Vehicles, acoustic surface wave detectors, and stand-off detectors mounted on helicopters using Light Detection and Ranging technologies. ${ }^{40}$ The counterproliferation program seeks to accelerate deployment of systems to detect WMD aerosols at ranges from five kilometers out to forty kilometers.

Passive defense improvements, seen as the final protective measures for forces, face severe challenges. As our Services become smaller with less resources, hard choices are necessary. The likelihood of WMD use against U.S. forces is often judged to be low to medium in intensity. Despite the catastrophic consequences of not being prepared for such a contingency, Pentagon officials often use the Services' WMD funds, now centrally managed by $\mathrm{DoD}$, to pay for other urgent modernization programs. The most recent example of this syndrome was when the Services, after going through the exhaustive justification and needs validation process of the JROC, lost one third (\$1B) of its modernization funds programmed for the next five years to an urgent need to modernize our truck fleet. National emergency or not, WMD defense and counterproliferation efforts will be easily overrun because it is difficult to sustain interest and support for a seemingly distant potentiality such as mass casualty weapons.

With a review of the Counterproliferation Support Program and the means of the Counterproliferation strategy, the emperor's new clothes become somewhat suspect. The eight ambitious elements of battlefield surveillance, strategic and tactical intelligence, 
proliferation prevention, counterforce, covert operations, active defense, and passive defense all look good on tailors' design patterns. However, meager investment in surveillance, no new funds for intelligence, questionable effectiveness of counterforce, policy conundrums with covert operations, insufficient investment in Theater Missile Defense aspects of active defense, and passive defense suffering bill-payer syndrome, create much apprehension in the adequacy of prevention and protection against weapons of mass destruction.

This assessment reviewed the current counterproliferation strategy via an ends, ways, and means methodology. Through National Security Strategy, National Military Strategy, Counterproliferation Initiative, and the Counterproliferation Support Program, this nation is taking strong and definitive steps against weapons of mass destruction and their means of delivery. By examining our multidimensional efforts, however, we see unfulfilled expectations and illusionary progress. To avoid accepting counterproliferation at face value, we should review actual accomplishments and develop some recommendations for improvement.

With so many erstwhile tailors struggling to create beautiful garments for the emperor, perhaps there is a lack of leadership to guide and focus their efforts. During several Senate investigative reviews, the question of "who is in charge" surfaces. By Executive Order 12938 (November 1994), the President is on record with declaring weapons of mass destruction a National Emergency and driving home the critical importance of addressing the problems of proliferation. The State Department, Department of Defense, Justice Department, Commerce Department, Federal Bureau of Investigation, and the Central Intelligence Agency representatives take long pause at the question of who is in charge. Reluctantly, they point to 
the National Security Council and a Special Advisor to the President who, perhaps, las the full time job of leading the efforts. If we have to think about it and bureaucratically trace who may be in charge, then pertaps there is a need for stronger leadership rather than loosely coondinated individual agencies which search for synergy in counterproliferation efforts.

The tailors are busy, in their own spberes of influence, creating a cloak of great beauty. Each agency valiantly pursues its solution within its own resources and frame of reference. Individually, it is unwise to criticize them. Collectively, however, they will need a master tailor, one who will synchronize individual talents and engineer separate efforts and contributions toward a unified protective garment. Traditionalism and bureaucratic competition can be overcome with the proper leadership.

Although counterproliferation is one of our mosi urgent priorities, the economy is the inajor factor influencing the emperor's clothes. Scarce resources create a competition between tailors who, while understanding the strategy, wil! instinctively seek dominance for budzot share. Counterproiffartion is complex and requises many tyos of efforts from many types of tailors. It is difficult to argue against holistic approaches, but someone must complete the measurements, draw the pattern, produce the cloth, cur, assemble, and sew the pieces of this complex strategy. With resources becoming less available cach year, we cannot afford redundant or misplaced efforts.

The environment of reduced resources should stimulate an examination of what each tailor spent so far and what they plan to spend. While cach has a similar but different mission based on agency charters and focus, a look at each contributor's priorities could reveal some divergent efforts. Eliminating redundancy and establishing more appropriate 
priorities could ultimately reduce costs and achieve the common objective. If national leadership exists, a master priority, direction, and focus could help streamline productivity and improve efficiency. The emperor wants beautiful clothes, but what is often taken for granted is that be wants them at reasonable costs.

While too many cooks may spoil the broth, too many tailors are not necessarily bad as long ss they have solid policy guidance and leadership. Since 1993, the most noticeable efforts amounted to creating policy regimes to "direct" efforts of nonproliferation and counterproliferation. With so meny political, economic, military, and technical facets of proliferation, many tailors will need to convene. Policy means different things to different people at different levels. We probably have enough policy emphasizing the importance of counterproliferaticn. Each day lost on policy refinement results in months or years lost in building credible capabilities. With broad guidance already laid, the publication of coordinated implementation plans represents the next level at which to marshall forces. The styreme task is to spur national leadithip to vigorouly manage the trogran.

This national leader is the President. Understanding he cannot tead to the day-to-day activities of managing the national effort, the best approach would be to strengthen his Special Advisor for Counterproliferation in the National Security Council (NSC). The NSC is the best place for centralized decision recommendations to the President. While interagency friction is always present, the NSC is the most powerful and influential location in the government which can provide synergy and focus to the many counterproliferation efforts. With the increased priorities established by the President, the Special Advisor for Counterproliferation can improve his mansgement of agencies toward more synchronized 
activities.

In addition to the need for stronger national leadership, recommendations emerge on proliferation traditionalism. Attempts to clarify what is nonproliferation and what is counterproliferation are clever but inconsequential activities. The National Security Council Memorandum, datad 18 February 1994, attempted to clarify differences by des:ibising nonproliferation as a full range of political, economic, and military tools and has stated counterproliferation refers to the activities of the DoD across the full range of 'J.S. efforts. Drawing lines only encourages turf battles and ugly budget share competition. Accepting counterproliferation as a broad range of activities, where all concerned agencies contribute to a consolidated national objective, will begin to erase the lines in the sand drawn by often selfserving governmental agencies. Thi ierp to combat traditionalism is largely intellectual, but extremely significant in achieving turowaratic unity in counterproliferation efforts.

Competing bureaucracics are natural. Like the tailurs, each in its own way strugles to create solutions and worls of yreat beauty. With stronger NSSC involvement, compatition may be turned into productive achievements rather than separate and loosely coordinated activities. In fact, as acceptance of a broader definition and applicability of counterproliferation grows, each governmental agency may realize that not any one agency possesses the capability to reduce WMD and the coordinated efforts of all are essential for improvement. Frequent coordination and planning sessions, driven by a more ag3ressive NSC would mold better cooperation. One area of counterproliferation which benefits from this enlivened approach is the renewed emphasis on nuclear, biological, and chemical counterterrorimm." While we have a long way to go, Congressional support, reprogrammed 
resources, and enhanced interagency cooperation will reinforce Tresidential and NSC commitment to the growing threat.

Without improvement to counterproliferation progress, our leaders are likely to parade with an imaginary cloak of protection. We need to stop throwing out endless policy regimes. We have enough policy, strategy, and initiatives. Overcoming nonproliferation traditionalism requires continued commitment and intellectual change. Competing bureaucracies can shift into productive and unified cooperation. It is now time to reexamine priorities to achieve realistic defensive capabilities. With stronger leadership, more synchronized interagency action, and rededication to counterproliferation focus, we can provide substance to the emperor's clothes.

In the post-Cold War era, the world is still a dangerous place. Froin the perspective of weapons of mass destruction and their means of delivery, the world is even more dengerous. The proliferation of WMD is still incressing. Although we can see progress in intersotional efiorts against proliferation by bilateral and multilateral treaties and weapons control agreements, nearly twenty-five nations have, or are working on offensive WMD programs. This condition will continue to threaten regional stabilities despite international condemnation. There is no guarantee that a nation, state, or group, when backed against the wall, will refrain from the use of WMD. Our traditional means of deterrence are questionable. Counterproliferation efforts, especially defensive improvements, are critical hodges against these threats. If counterproliferation continues to be simply well-heeled policies and promises of improved capabilities, who will tell the cmperor that he has no clothes? 


\section{ENDNOTES}

'Michael Wheeler et al, Implications of the Counterstelifortion Initiative for the US. Amy, (Mclean, VA: SAIC, 1994), 1.

${ }^{2}$ Robert G. Joseph, "WMD: A Proli.eration Overview," in Weapons of Mass Destriction: Nevr Resspectives on Countessoliferation, Center for Counterproliferation Research, (Washington DC: National Defense University Press, 1995), 4.

'Lewis A. Dunn, "Proliferation Prevr ation: Beyond Traditionalism," in Wencons of

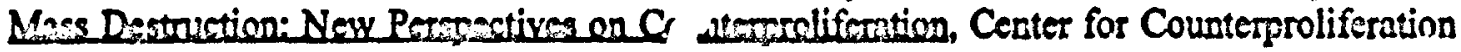
Reseasch, (Washington, DC: National Def ise University Press, 1995), 27.

'President Bill Clinton, White House Press Release, Executive Order 12938, (Wathington DC, May 18, 1995).

SJohn M.. Shalikashvili, National Military Stretery of the United States nf America: A Stretasy of Elexible and Selective Engazement, (Washington, DC: USGPO, 1995), i.

'President Bill Clinton, ANrtionsl Stmetesy of Enezgement and Enlarcemant, (Washington DC: USGPO, 1995), 13.

'Shalikashvili, 4.

'Tbid, 8, 10, 11, 16.

'Dunn, 28.

${ }^{10}$ Wheeler, 5.

"Les Aspin, "Counterproliferation Initiative," remarks to the National Academy of Sciences, Committee on International Security and Arms Control, 7 Dec 1993.

${ }^{12}$ Mitchel B. Wallerstein, "Concepts to Capabilities: The First Year of Counterproliferation," Wercons of Mass Destnuctioni.New Peressatives on Coumismedifertion Center for Counterproliferation Research, (Washington DC: National Defense University Press, 1995), 22.

"Wallerstein, 23.

"Wheeler, 96. 
'Tbid, 97.

19Tbid, 98.

'Tbid, 99.

"Tbid, 100.

Tibid, 101.

${ }^{20}$ Tbid.

21Ibid, 102.

${ }^{2}$ Jeff Eslich and Theresa Hitchens, "Counterproliferation Efforts Await Requirement Review," Defense News, Nov 6-7, 1995, 20

23"Counterntroliferation of Weapons of Mass Destruction", based on the National Security Science and Technology Strategy, Defence 95, Issue 6 (Washington DC: USGPO), 8.

${ }^{24}$ Erlich and Hitchens, 20.

${ }^{25}$ The Weapons Proliferation Threas, Nonproliferation Center, (Washington DC: Dirsctor of Central Intelligence, Mar 1995), 7.

${ }^{26}$ Erlicb and Hitchens, 20.

${ }^{27}$ Ithe Weapons Proliferation Threat, 7

${ }^{2 t}$ Erlich and Hitchens, 20.

Ibid.

${ }^{30}$ Defense $95,8$.

"Erlich and Hitchens, 20.

32 James Woolsey, Testimony to Senate Select Committee on Intellicence, Jan 1994

${ }^{31}$ The Weapons Proliferation Thress, 2.

"Wheeler, iii.

${ }^{35}$ Erlich and Hitchens, 20.

sibid. 
${ }^{37}$ Steve Kosiak, "Nonprolifention and Counterproliferation: Investing for a Safe: World?' Defence Budaet Project, (1995): 33, 35.

${ }^{3}$ Dr. Gordon C. Olehler, The Chemical and Biological Weanons Threat Statement for the Record, to the Permanent Subcommittee on Investigations of the Senste Committee on Govemment Affairs, (Washington DC, Director of Central Intelligence, 1 Nov 1995), 1,10,12.

3rwechnologies Underlying Weapons of Mass Destruction," Office of Technology Assessment, US Congress, 1993.

${ }^{40}$ Erlich and Hitchens, 20.

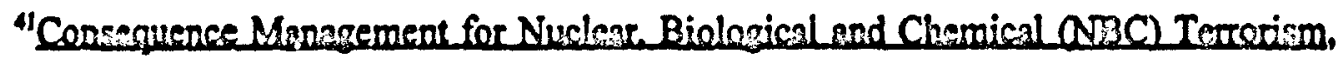
Status Report to the President, (Washington DC: Federal Emergency Manazement Agency, 1995), 2. 


\section{BIBLIOGRAPHY}

Aspin, Les. "Counterproliferation Initiative," remarks to the National Academy of Sciences, Committee on International Security and Arms Control, 7 Dec 1993.

Clinton, President Bill. White House Press Release, Executive Order 12938. Washington DC: May 18, 1995.

Clinton, President Bill. A National Strateoy of Engagement and Enlarsement. Washington DC: USGPO, 1995.

Croddy, Er.c. "Urban Terrorism-Chemical Warfare in Japan," Jane's Intelliaence Review, Nov 95.

Department of Defense. "Counterproliferation of Weapons of Mass Destruction", based on the National Sccurity Science and Technology Strategy, Defenee 25, Issue 6, Wash DC.

Dunn, Lewis A. "Proliferation Prevention: Beyond Traditionalism," in Wonens of Mass Detnuction: New Perspectives on Countenprolifenation. Center for Counterproliferation Research, Washington, DC: National Defense University Press; 1995.

Erlich, Jeff and Hitchens Theresa. "Counterproliferation Efforts Await Requirement Review," Defense News, Nov 6-7, 1995.

Federal Emergency Management Agency. Coneauanee Mananement for Nuclear Biological and Chomical (NBC) Terrotism. Status Report to the President, Washington DC:, 95.

General Accnunting Office, Chemical and Biological Defense: US Forces Net Adeguately Equipped te Detect all Threats, Report to the Chaiman, Committee on Governmental Affairs, US Senate, Washington DC, 1993.

Jackson, Richard A. Nuclear. Biologiczl and Chemisal Defenes in tbe 21 st Ceatury. Center for Strategic Leadership, Carlisle, PA, 1995.

Jenkins, Brian M. "The Future Course of International Terrorism," The Funurist, Jul-Aug 95.

Joseph, Robert O. "WMD: A Proliferation Overview," in Weapens of Mass Destruction: New Peranectives on Countarproliferation. Center for Counterproliferation Research, Washington DC: National Defense University Press, 1995.

Joseph, Robert G. and Reichart, John R. Detzucnceand Defense in a Nuslear Bioleojcal and Chemical Environment, Center for Cousterproliferation Researcb, Washirgton DC: National Defense University Press, 1996.

$$
24
$$


Krishnsswami, Sundarji. "Proliferation and the Security Dimeasions in South Asia: An Indian

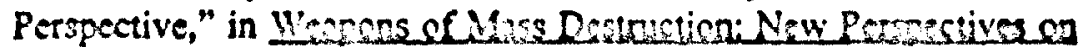

Couneswelifintiog. Center for Counterproliferation Research, Washington DC, National Defence Uaiversity Press, 1995.

Kosiak Steve. "Nonproliferation and Counterproliferation: Investing for a Sufer World?" Defense Budigt Proied 1995.

Kufperman, Robert H. "United States Becoming Target for Terror Forays," National Defonce, January 1995, 22-23.

Nonpmliferation Center. The Wearons Proliferation Threst. Washington DC: Directur of Central Inielligence, Mar 1995.

Olchler, Dr. Gordon C. The Chemical and Bidozisal Weanons Throat Statement for the Record, to the Pemmanent Subcommittee on Investigations of the Sezute Commit.se on Government Affairs, Washington DC, Director of Central Intelligence, 1 Nov 1995.

Onice of Technology Assessment. "Technologies Underly ing Weapons of Mass Destruction.". US Congress, 1993.

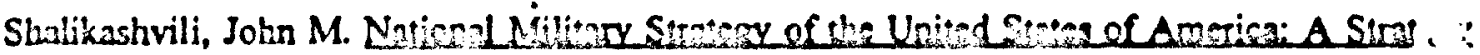

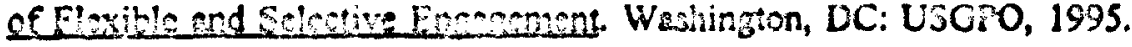

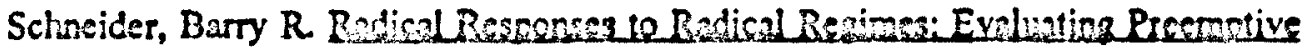
Countineroliferation. National Detense University, Washingion DC, 1995

Wallerstein, Mitchel B. "Concepts to Capabilities: The First Year of Counterproliferation,"

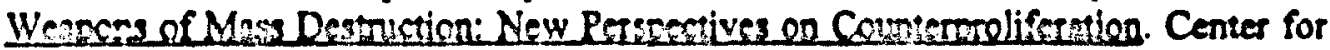
Counterproliferation Research. Washirgton DC: National Defense University Press, 1995.

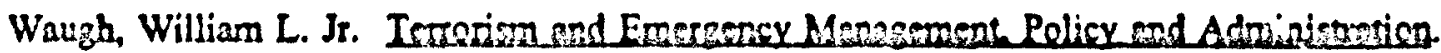
Marcel Dekker Inc, New York, 1990.

Wheeler, M., Brooks, B., Doyle, J., and Rhoedes, R. Imndirntions of the Counteromeliferation Lritiotive for the US.Amn. Mclean, VA: SAIC, 1994.

Woolsey, James. Testimony to Senate Select Comrittee on Intelligence, Jan 1994. 